\title{
The effect of psychosis associated CACNA1C, and its epistasis with ZNF804A, on brain function
}

Short title: The effect of CACNA1C on brain function

Diogo Tecelão', BSc, Ana Mendes², MSc, Daniel Martins ${ }^{3}, \mathrm{MD}$, Cynthia $\mathrm{Fu}^{4}, \mathrm{PhD}$, Christopher A Chaddock ${ }^{5}, \mathrm{PhD}$, Marco M Picchioni ${ }^{5,6}$, PhD, Colm McDonald ${ }^{7}, \mathrm{PhD}$, Sridevi Kalidindi ${ }^{5}, \mathrm{PhD}$, Robin Murray ${ }^{5}, \mathrm{PhD}$, Diana P $\underline{\text { Prata }}^{3,8 \S}, \mathrm{PhD}$

${ }^{1}$ Departamento de Física, Faculdade de Ciências e Tecnologia da Universidade Nova de Lisboa

${ }^{2}$ No affiliation

${ }^{3}$ Department of Neuroimaging, Institute of Psychiatry, Psychology \& Neuroscience, King's College London, London, UK

${ }^{4}$ School of Psychology, The University of East London, London, UK

${ }^{5}$ Department of Psychosis Studies, Institute of Psychiatry, Psychology \& Neuroscience, King's College London, London, UK

${ }^{6}$ St. Andrew's Academic Department, St Andrew's Healthcare, Cliftonville, Northampton, UK Centre for Neuroimaging and Cognitive Genomics (NICOG) \& NCBES Galway Neuroscience Centre, College of Medicine, Nursing and Health Sciences, National University of Ireland Galway, H91 TK33, Galway, Ireland

${ }^{8}$ Instituto Universitário de Lisboa (ISCTE-IUL), Cis-IUL, Lisbon, Portugal

This is the author manuscript accepted for publication and has undergone full peer review but has not been through the copyediting, typesetting, pagination and proofreading process, which may lead to differences between this version and the Version of Record. Please cite this article as doi: $10.1111 / \mathrm{gbb} .12510$

This article is protected by copyright. All rights reserved. 
${ }^{\S}$ corresponding author (diana.prata@medicina.ulisboa.pt, +351 966595936)

Keywords: $C A C N A 1 C, Z N F 804 A$, verbal fluency, genome-wide association, schizophrenia, bipolar disorder, psychosis, functional magnetic resonance imaging, imaging genetics, functional connectivity, psychophysiological interaction.

\section{Date of submission}

$22 / 02 / 2018$

\section{Word counts}

Abstract: 248

Introduction: 1173

Methods: 1844

Results: 1064

Discussion: 1695

Conclusion: 155

Total: 9958

This article is protected by copyright. All rights reserved. 


\begin{abstract}
$C A C N A 1 C$-rs1006737 and ZNF804A-rs1344706 polymorphisms are amongst the most robustly associated with schizophrenia (SCZ) and bipolar disorder (BD), and recently with brain phenotypes. As these patients show abnormal verbal fluency (VF) and related brain activation, we asked whether the latter was affected by these polymorphisms (alone and in interaction) - to better understand how they might induce risk. We recently reported effects on functional VF-related (for ZNF804A-rs1344706) and structural (for both) connectivity.

We genotyped and fMRI-scanned $54 \mathrm{SCZ}, 40 \mathrm{BD}$ and 80 controls during VF. With SPM, we assessed the main effect of $C A C N A 1 C$-rs 1006737, and its interaction with ZNF804Ars1344706, and their interaction with diagnosis, on regional brain activation and functional connectivity (psychophysiological interactions - PPI). Using public data, we reported effects of $C A C N A 1 C$-rs 1006737 and diagnosis on brain expression.

The $C A C N A 1 C$-rs 1006737 risk allele was associated with increased activation, particularly in the bilateral prefronto-temporal cortex and thalamus; decreased PPI, especially in the left temporal cortex; and gene expression in white matter and the cerebellum. We also found unprecedented evidence for epistasis (interaction between genetic polymorphisms) in the caudate nucleus, thalamus, and cingulate and temporal cortical activation; and CACNA1C up-regulation in SCZ and BD parietal cortices. Some effects were dependent on BD/SCZ diagnosis. All imaging results were whole-brain, voxel-wise, and familywise-error corrected.
\end{abstract}


Our results support evidence implicating CACNAIC and ZNF804A in BD and SCZ, adding novel imaging evidence in clinical populations, and of epistasis - which needs further replication. Further scrutiny of the inherent neurobiological mechanisms may disclose their potential as putative drug targets.

\section{Introduction}

Schizophrenia (SCZ) and bipolar disorder (BD) are severe psychiatric diseases with a strong genetic component (a heritability of up to $80 \%$ in SCZ (Cardno et al. 1999) and 93\% in BD (Kieseppä et al. 2004)). Recently, genome-wide association studies (GWAS) have identified CACNA1C and ZNF804A as significant risk genes for both SCZ and BD susceptibility (Gurung \& Prata 2015). Nevertheless, how they induce risk for psychiatric illness remains relatively unknown.

CACNA1C encodes an alpha-1 subunit of the voltage dependent L-type calcium channel $\mathrm{Ca}_{\mathrm{v}}$ 1.2. This type of channels is widely expressed in the brain and involved in, for example, regulation of signalling pathways, neurotransmitter release, synaptic plasticity, neuron excitability and specifically modulates the effects of synaptic activity on cell survival (Uemura et al. 2015). The rs1006737 single nucleotide polymorphism (SNP) of the CACNAIC gene was identified through GWAS to be associated with risk for both BD (Ferreira et al. 2008) and SCZ (Green et al. 2010; Nyegaard et al. 2010). This risk allele adenine (A) of this SNP was also associated independently with: 1) increased CACNA1C mRNA expression (which might affect the receptor's activity (Bigos et al. 2010)) in induced human neurons; 2) increased density of $\mathrm{Ca}_{\mathrm{v}} 1.2$-mediated currents (Yoshimizu et al. 2015); and 3) decreased expression in the human cerebellum (Gershon et al. 2014). This may 
suggest that either an increase or decrease of calcium influx in excitable cells might be associated with $\mathrm{SCZ}$ or $\mathrm{BD}$, as both could lead to changes in monoamine neurotransmitter synthesis and release (Gershon et al. 2014) - which has, indeed, been associated with other psychiatric disorders (Booij et al. 2003).

In terms of anatomy, the same $C A C N A 1 C$ rs1006737 risk allele, has been associated with increased total and fronto-limbic white matter volume (Frazier et al. 2014), albeit only after a few earlier negative findings (Kempton et al. 2009; Franke et al. 2010). Regarding white matter, after a reported association with reduced microstructural integrity in the right hippocampal formation in healthy Caucasians (Dietsche et al. 2014), we have published, for the first time using whole-brain tract-based spatial statistics, an association with reduced microstructural integrity. This effect was found within SCZ subjects (but not controls or BD), in portions of the left middle occipital and para-hippocampal gyri, right cerebellum, left optic radiation and left inferior and superior temporal gyri (Mallas et al. 2016a) - consistent with previous voxel-based findings (Woon et al. 2014). We also found the first evidence of an additive interaction of the $C A C N A 1 C$ and $Z N F 804 A$ genotype on white matter microstructure (Mallas et al. 2016a). Both risk alleles' concomitant presence in BD was associated with decreased integrity in the body of the corpus callosum, the right superior and left anterior corona radiata, comparatively more than in healthy controls. This finding is consistent with the hypothesis that both these polymorphisms increase risk for psychosis.

In terms of brain function, healthy risk allele (A) carriers have shown: 1) a trend for increased left precuneus and left inferior frontal activation in healthy volunteers during semantic verbal fluency (Krug et al. 2010) and, 2) a trend for increased prefrontal activation during working memory (Bigos et al. 2010). Both frontal effects, given that performance level was controlled 
for, could be interpreted as lower efficiency - which is also found in SCZ relatively to controls (Gurung \& Prata 2015). However, the latter was contested by another study that surprisingly found the reverse effect in healthy subjects: the risk allele homozygous showing less activity vs. G-allele carriers in the right dorsolateral prefrontal cortex (Paulus et al. 2014). Increased functional connectivity between that region and the bilateral hippocampal formations (dose-dependently) was also found, which, interestingly, mimics some ZNF804A rs1344706 risk allele's findings, suggesting a common downstream pathway for both risk variants (Gurung \& Prata 2015). As replication is key to clarify cause-effect assumptions in correlational approaches, we asked whether we could re-produce the above pattern of findings for CACNAIC's role on brain function - and help clarify inconsistencies.

Regarding the impact of ZNF804A rs1344706 genotype, the risk allele $\mathrm{A}$ has been extensively associated with alterations in connectivity, and, to a lesser extent, in brain activation (Gurung \& Prata 2015). The risk allele A was recently associated in verbal fluency with decreased functional coupling between the left precentral gyrus/inferior frontal gyrus and both the left inferior frontal gyrus and the left posterior cingulate gyrus, encompassing the precuneus (Tecelão et al. 2018). This converges with findings showing intra- and interhemispheric prefrontal connectivity decrease (albeit not always) in other tasks (Gurung \& Prata 2015), abnormal white matter microstructure (Mallas et al. 2016b), and with the disconnection hypothesis of SCZ (Gurung \& Prata 2015). Finally, the risk allele A was also associated during verbal fluency with higher regional activation in $\mathrm{BD}$, but the reverse in healthy controls, in the left inferior frontal gyrus, pars opercularis/triangularis (Tecelão et al. 2018), supporting a previous finding in healthy subjects during theory-of-mind (Gurung \& Prata 2015). 
Thus, in addition, in this study we assessed, for the first time, interaction between these polymorphisms (i.e. epistasis) in clinical samples of BD and SCZ. We inferred the main effect of $C A C N A 1 C$ rs1006737 genotype (or, rather, the linkage disequilibrium block it tags) and its interaction with ZNF804A rs1344706 genotype, on regional brain activations and functional connectivity, including that under psychophysiological interaction (PPI), during verbal fluency - across healthy volunteers, and SCZ and BD patients. We also tested for genotype associations that would be dependent on diagnosis. We used verbal fluency as we, using an overlapping sample to the present one (Prata et al. 2009a), and others, have shown that it is (Curtis et al. 1998, 1999, 2001; Fu et al. 2005) - as are its neural correlates (Krabbendam et al. 2005; Daban et al. 2006) - impaired in psychosis, especially in SCZ. $C A C N A 1 C$ risk allele A was expected to be associated with less efficient regional activation and with functional connectivity disruptions during verbal fluency. This is given previous evidence of its effect on regional activation (Bigos et al. 2010; Krug et al. 2010), and functional (Paulus et al. 2014) and structural (Dietsche et al. 2014; Woon et al. 2014; Mallas et al. 2016a) connectivity. We also expected that these individual effects of the risk allele might be augmented by the presence of the risk allele A of ZNF804A rs1344706 which we have recently found to have a putatively detrimental effect during the same task and sample as the present ones - i.e. of decreased left ipsilateral prefrontal functional connectivity across diagnoses (Tecelão et al. 2018). In other words, we predicted that the presence of both risk alleles would be associated with the most inefficient activation and/or disrupted functional connectivity - mimicking our abovementioned findings in white matter (Mallas et al. 2016a). To lend possible converging evidence to our neuroimaging findings, we further enquired, using an online public brain gene expression database, whether these SNPs affected gene 
expression (i.e. were expression quantitative trait loci; eQTLs) in each of 10 post-mortem human brain areas. With a second database, we tested diagnosis-wise differences in these genes' expression in several brain areas (comparing SCZ, BP and healthy subjects).

\section{Materials and Methods}

\subsection{Sample}

Our sample consisted of 174 English native speakers, the majority (93\%) Caucasian, including a control group comprised of 80 healthy volunteers (34 males, $39 \pm 13$ y.o.) with no history, or first degree family history, of a psychotic spectrum disorder, 54 patients with established SCZ (42 males, $37 \pm 11$ y.o.) and 40 with BD (16 males, $40 \pm 12$ y.o., $75 \%$ of which with a history of psychosis). Patients were recruited from the South London and Maudsley (SLaM) NHS Trust. Diagnosis, according to the criteria of the Diagnostic and Statistical Manual of Mental Disorders (DSM) $4^{\text {th }}$ Edition (American Psychiatric Association 1994), was ascertained by an experienced psychiatrist using a structured diagnostic interview with instruments detailed elsewhere (Prata et al. 2009b). All SCZ and BD patients were in a stable clinical state. Exclusion criteria applied to all participants were a history of significant head injury and current (last 12 months) substance dependency according to DSM-IV diagnostic criteria. The study was approved by the National Health Service (NHS) South East London Research Ethics Committee, UK (Project “Genetics and Psychosis (GAP)” reference number 047/04). All subjects gave written informed consent.

Genotyping for the CACNA1C rs1006737 and the ZNF804A rs1344706 SNPs was performed using standard genotyping techniques we previously described (Mallas et al. 2016a, 2016b). Possible genotype outcomes for CACNA1C were A homozygous (AA, 
adenine-adenine), heterozygous (AG, adenine-guanine) and $\mathrm{G}$ homozygous (GG, guanineguanine), and for ZNF804A were A homozygous (AA, adenine-adenine), heterozygous (AC, adenine-cytosine) or $\mathrm{C}$ homozygous (CC, cytosine-cytosine). Given the unbalanced frequency of allele counts in the Caucasian population (very low frequency of the allele A for the CACNA1C genotype and the allele C for the ZNF804A genotype), we grouped the CACNA1C risk allele A homozygotes with the CACNA1C heterozygotes (AA+AG) and the ZNF804A non-risk allele $\mathrm{C}$ homozygotes with the ZNF804A heterozygotes (AC+CC). Quality control-wise, the distribution of Caucasian genotype frequencies for the CACNA1C (0.18 AA, 0.42 AG, $0.40 \mathrm{GG})$ and the ZNF804A (0.46 AA, 0.39 AC, 0.15 CC) was consistent with Hardy-Weinberg Equilibrium, in patients $\left(\mathcal{C}^{2}\right.$ $(\mathrm{ZNF} 804 \mathrm{~A} / \mathrm{CACNA} 1 \mathrm{C})=1.60 / 1.69, \quad \mathrm{df}=1, \quad \mathrm{p}$-value $=0.21 / 0.19 \quad$ and $\quad$ controls $\quad\left(C_{\zeta}^{2}\right.$ $(\mathrm{ZNF} 804 \mathrm{~A} / \mathrm{CACNA} 1 \mathrm{C})=1.07 / 0.84, \mathrm{df}=1, \quad \mathrm{p}$-value $=0.30 / 0.36) . \quad$ Sample size,$\quad$ in each diagnostic group, and for a ZNF804A and CACNA1C genotype-genotype combination were, respectively: 1) in healthy controls: $26 \mathrm{AA}-[\mathrm{AA}+\mathrm{AG}], 14 \mathrm{AA}-\mathrm{GG}, 23$ [AC+CC]-[AA+AG], and $17[\mathrm{AC}+\mathrm{CC}]-\mathrm{GG}$; 2) in $\mathrm{BD}$ patients: $11 \mathrm{AA}-[\mathrm{AA}+\mathrm{AG}], 6 \mathrm{AA}-\mathrm{GG}, 14$ [AC+CC][AA+AG], and 9 [AC+CC]-GG; and 3) in SCZ patients: 16 AA-[AA+AG], 11 AA-GG, 16 $[\mathrm{AC}+\mathrm{CC}]-[\mathrm{AA}+\mathrm{AG}]$, and $11[\mathrm{AC}+\mathrm{CC}]-\mathrm{GG}$. The sample's demographics are described in detail in Supplementary Table 1.

Demographic differences between diagnostic and/or genotype groups were analysed using the $\mathrm{R}$ software ( $\mathrm{R}$ Core Team 2016) using Ģsquare tests for categorical variables and independent $t$-tests and analysis of variance (ANOVA) for continuous variables. There were no significant differences in age, years of education, ethnicity or handedness between the 
groups of diagnosis, genotypes or genotypes in each diagnosis. As expected, IQ significantly differed $(\mathrm{p}<0.001)$ between diagnoses, being significantly lower in SCZ compared to controls (or BD) - but there were no significant differences in IQ between genotype groups (of either gene). Diagnoses also significantly $(\mathrm{p}<0.001)$ differed in gender with more males in SCZ than in BD and more females in controls than in SCZ. The patient groups differed in chlorpromazine $(\mathrm{CPZ})$ equivalents in medication $(\mathrm{p}<0.001)$ with $\mathrm{SCZ}$ having a higher load than $\mathrm{BD}$, as expected given current treatment strategies.

\subsection{Verbal Fluency Task and Image Acquisition}

The verbal fluency task and image acquisition was performed as previously described elsewhere (Fu et al. 2002) (see Supplement 2 for details). Briefly, subjects were required to overtly generate a word starting with a visually displayed letter; or overtly read the word "rest" (control or "repetition" condition). Task difficulty, although not factored in the group analysis, was manipulated by presenting separate, and counterbalanced, sets of "easy" and "hard" letters (Fu et al. 2002).

\subsection{Neuroimaging Analysis}

Data preprocessing was performed using SPM software (University College London, UK) running under Matlab 8.3 (The Mathworks, Inc., USA). All volumes from each subject were realigned and unwarped (using the first slice as reference), with a separation of $4 \mathrm{~mm}$ between the points sampled in the reference image, a $5 \mathrm{~mm}$ full width at half maximum (FWHM) isotropic Gaussian kernel applied to the images before estimating the realignment parameters, and $2^{\text {nd }}$ degree B-spline interpolation. Normalization to the functional MNI template (EPI) 
was then performed using a voxel size of $2 \times 2 \times 2 \mathrm{~mm}$ and trilinear interpolation. Spatial smoothing was carried out with an $8 \mathrm{~mm}$ FWHM isotropic Gaussian kernel. The remaining realignment, unwarping, normalization and smoothing parameters corresponded to the default choices.

After the pre-processing steps, statistical analysis of regional responses in a subject-specific fashion was performed using SPM, by convolving each onset time with a synthetic haemodynamic response function (HRF) (Mechelli et al. 2008). The ensuing event-related (general linear) model comprised five experimental regressors: 1) easy; 2) repetition-easy; 3) hard; 4) repetition-hard; 5) incorrect responses. The latter was excluded from the group analysis so we could control for differences in task performance (and, as such, restrict our inferences to scans corresponding to correct responses). Data were high-passed filtered with a cut-off period of 128s using a set of discrete cosine basis function. Parameter estimates were calculated for all brain voxels using a general linear model,and contrast images for 'verbal fluency (easy plus hard) > repetition (easy plus hard)' were computed for each subject to test for a main effect of task. The second (between-subject or group) level inferences were made using the standard summary statistic approach. This involved entering the subject-specific contrast images for "verbal fluency (easy plus hard) >repetition (easy plus hard)" into a 3x2x2 full-factorial ANOVA ('Diagnosis'x'ZNF804A-genotype'x'CACNA1C-genotype'). [A complementary analysis was performed where the levels of 'Diagnosis' were 'healthy volunteers' and 'patients with psychosis' (i.e. all SCZ plus $75 \%$ of the BD patients)]. Since the superior region of the prefrontal cortex was not scanned in a sub-group of subjects, it was automatically excluded from the group analyses. We tested the main effect of $C A C N A 1 C$ genotype and of its interaction with ZNF804A genotype and/or with diagnosis. The main 
effect of ZNF804A genotype is not reported herein, as it has already been reported in a previous study using the same sample (Tecelão et al. 2018), and the effect of task has also been described in a highly overlapping sample (Prata et al. 2009a). The main effect of diagnosis is reported as supplementary material, as it has been discussed using a subset of the present sample earlier (Prata et al. 2009a).

For functional connectivity, we used the same subject and group-level models as above, this time using (instead of activation) coupling (i.e. time-correlated activation) between each subject-specific seed region and the remaining brain. Those seeds were defined, per subject, as the coordinates where the main effect of task was the highest, within a 6-mm radius sphere ROI centred on the group maximum (i.e. left precentral gyrus/inferior frontal gyrus, pars opercularis, tagged by its peak coordinates: -44434$)$. To test for condition-specific changes in connectivity we used a PPI analysis, using the same previous subject and group level models and the seed approach as above. By including an interaction between the physiological and the psychological (verbal fluency) regressors, we tested for the ensuing psychophysiological interaction. Effectively, this reflects the change in directed (effective) connectivity mediated by the task - as evaluated under a simple linear model of coupling between the seed region and the remaining brain. The PPI regressor was formed by multiplying the seed time-series with the HRF convolved task (using "verbal fluency (easy plus hard) $>$ repetition (easy plus hard)" contrast). The resulting PPI vector was then used as a regressor in the subject-level analysis, with both the seed time-series and the HRF convolved task as covariates of no interest. 
In addition to a whole-brain approach, we ran one additional analysis with selected regionsof-interest (ROIs) reported in two previous studies finding an effect of CACNA1C rs1006737 in semantic verbal fluency (Krug et al. 2010) and working memory (Bigos et al. 2010). These ROIs were derived from the automated anatomical atlas (AAL) (Tzourio-Mazoyer et al. 2002) and the Talairach Daemon database in Wake Forest University PickAtlas (Lancaster et al. 1997, 2000; Maldjian et al. 2003) (version 3.0.5). From the former (Krug et al. 2010) we derived a mask formed by the left precuneus and inferior frontal gyrus, and from the latter (Bigos et al. 2010), one comprising the Brodmann areas 9, 10 and 46. Additionally, the selected ROI masks were also defined using $10 \mathrm{~mm}$ spheres centred in their respective peak coordinates (obtained from the given studies). These post-hoc analyses allowed us to further clarify inconsistences in the published literature.

Significant findings are reported as so, if they survive voxel-wise familywise rate error (FWE) correction for multiple comparisons at $\mathrm{p}<0.05$ across the whole brain (or within the ROI, for the ROI analyses), and at a cluster size e5. All other results are considered 'trends'. In order to assess how much of the inter-individual (+ error) variance in blood oxygen leveldependent activation on the voxel of peak effect of each reported effect was explained by genotype, we calculated the $\eta_{\mathrm{p}}{ }^{2}$ (partial eta squared) measure of effect size using R software (R Core Team 2016). Brain regions are labelled using an automatic-labelling atlas (TzourioMazoyer et al. 2002) and confirmatory visual inspection of a manual book atlas (K. Mai et al. 2008). Post-hoc analysis exploring the driving force of the significant interaction effects between genotypes and/or diagnosis are contained as supplementary material. Finally, in order to ascertain that none of our extraneous variables confounded, or added significant 
noise to our imaging results, extra analyses were performed as described in supplementary material 2.

\subsection{Gene expression analyses}

To test whether the CACNAIC rs1006737 risk variant (or other variants tagged by it in the same linkage disequilibrium block) affected any genes' mRNA expression level (i.e. was an eQTL), we used the publicly available Braineac database - which includes genotypic and microarray profiling of 10 brain regions of 134 neuropathologically normal individuals with European descent (Ramasamy et al. 2014) (cerebellar cortex, frontal cortex, hippocampus, medulla oblongata, occipital cortex, putamen, substantia nigra, temporal cortex, thalamus, and intralobular white matter). Expression levels from exon-specific probes and total transcripts (Winsorised mean over exon-specific levels) were used to determine the association between this SNP and the expression of mRNA of all genes distant less than $1 \mathrm{MB}$ (cis-eQTL analysis), considering its transcription initiation site. We focused on cis-eQTL associations as these are more likely to truly reflect direct effects of a genomic variant on gene expression (Bryois et al. 2014). More detailed information is described in the Braineac database (Ramasamy et al. 2014). The same approach was followed for ZNF804A rs1344706 in our recent paper regarding that gene (Tecelão et al. 2018).

For completeness, we also analysed Allen Brain Atlas data to define maps of CACNA1C expression in the human brain. Normalized $\log 2$ expression data relative to 3 probes targeting CACNA1C mRNA were downloaded. The probe presenting higher variance was selected based on the fact that it may more accurately represent gene distribution across the brain 
structures available. Mean-normalized z-scores were then calculated. Enriched areas were defined for a threshold of Z-score $>1$.

\section{Results}

\subsection{Regional activation}

\section{Effect of genotype}

\subsubsection{Main effect of CACNA1C}

Irrespective of diagnosis, the $C A C N A 1 C$ rs 1006737 risk allele $A$ was significantly associated (voxel-level FWE $\mathrm{p}<0.05)$ with greater activation in the right $(R)$ thalamus $(Z=4.44$, $\left.._{\mathrm{p}}^{2}=2.95 \%\right)$, and the left $(\mathrm{L})$ middle frontal gyrus $(\mathrm{Z}=4.32$; Figure 1; Table 1). At a trend level (i.e. with a cluster less than 5 voxels, $\mathrm{k}<5$ ), the same effect was found in the $\mathrm{L}$ thalamus $\left(\mathrm{Z}=4.27, \cdot{ }_{\mathrm{p}}^{2}=3.02 \%\right)$.

When inspecting each diagnostic group separately, we found that in the BD group alone, the above effect was also significant (whole-brain voxel-level FWE $p<0.05$ ) in some of the above areas, plus others: the $\mathrm{R}$ thalamus $\left(\mathrm{Z}=4.89, \cdot{ }_{\mathrm{p}}{ }^{2}=17.7 \%\right)$, the $\mathrm{L}$ middle $(\mathrm{Z}=4.71$ and $\mathrm{Z}=4.21)$ and superior $(Z=4.56)$ frontal gyrus, the $R$ superior $(Z=4.53)$ and middle $(Z=4.47$ and $\mathrm{Z}=4.25$ ) temporal gyri and, as a trend, in the $\mathrm{L}$ calcarine sulcus (occipital gyrus; $\mathrm{Z}=4.28$ and $\mathrm{Z}=4.22$ ). The same genotype had an effect in another region of the $\mathrm{R}$ middle temporal gyrus $(Z=4.25)$ but associated with decreased deactivation. No other diagnostic group alone showed significant effects of $C A C N A 1 C$ genotype.

When inspecting only patients with a history of psychosis, we found that the risk allele $A$ was associated as a trend with decreased deactivation in the $R$ precuneus $\left(Z=4.24, \cdot{ }_{p}^{2}=9.61 \%\right)$. 


\subsubsection{CACNA1C by diagnosis interaction}

The effect of increased activation associated with risk allele A was significantly (voxel-level FWE $\mathrm{p}<0.05$ ) higher in $\mathrm{BD}$ than in healthy volunteers in the superior temporal gyrus bilaterally $\left(\mathrm{Z}=4.72, \cdot{ }_{\mathrm{p}}^{2}=7.35 \%\right.$ and $\mathrm{Z}=4.29,{ }_{\mathrm{p}}{ }^{2}=6.52 \%$; Figure 2$)$ and $\mathrm{R}$ middle temporal gyrus $(Z=4.53)$. The same effect was found in the $L$ occipital gyrus $(Z=4.67)$, the $L$ calcarine sulcus (occipital gyrus; $Z=4.34$ and $Z=4.30$ ) and $L$ lingual gyrus $(Z=4.21)$. Furthermore, this effect was found as a trend in the $\mathrm{R}$ angular gyrus $(\mathrm{Z}=4.36$; in which it signified lower deactivation), and in the $\mathrm{L}$ middle frontal gyrus $(\mathrm{Z}=4.24)$. The same genotype effect was also higher as a trend in SCZ patients than in controls in the R inferior frontal gyrus, pars opercularis $\left(Z=4.31, \cdot{ }_{\mathrm{p}}^{2}=7.41 \%\right)$. No significant interaction effects were found when contrasting BD and SCZ.

The effect of increased activation associated with the risk allele A mentioned above in the $\mathrm{L}$ calcarine sulcus (occipital gyrus; $\mathrm{Z}=4.69, \cdot{ }_{\mathrm{p}}^{2}=7.32 \%$ ) and in the $\mathrm{L}$ middle frontal gyrus $(\mathrm{Z}=4.30)$, but not in the other regions, was significantly higher in psychotic patients as a whole than in healthy volunteers (voxel-level FWE $\mathrm{p}<0.05$ ).

\subsubsection{CACNA1C by ZNF804A genotype epistasis}

Irrespective of diagnostic group, there was no significant interaction between genotypes anywhere in brain.

This article is protected by copyright. All rights reserved. 
When inspecting the healthy volunteers group alone, a significant 2-way genotype (at wholebrain voxel-level FWE $\mathrm{p}<0.05$ ) interaction was found (Table 1): CACNA1C risk allele carriers activated less than non-risk allele homozygotes, within the ZNF804A risk allele homozygotes group, but the reverse was seen for ZNF804A non-risk allele carriers. This effect was found bilaterally in the precuneus $\left(Z=5.05, \cdot{ }_{p}^{2}=15.39 \%\right.$ and $\left.Z=4.73\right)$, posterior cingulate gyrus $(Z=5.05$ and $Z=4.42$ ), calcarine sulcus (occipital gyrus; $Z=4.42$ and $Z=4.31$ ) and thalamus $(Z=4.75,4.64$ and $Z=4.40)$. This same effect was found as a trend $(k<5)$ in the L lingual gyrus $(Z=4.26), R$ middle cingulate gyrus $(Z=4.24)$ and $R$ superior temporal gyrus $(\mathrm{Z}=4.21)$. (Note that, bilaterally in the precuneus and posterior cingulate gyrus and in the $\mathrm{R}$ calcarine sulcus (occipital gyrus) and superior temporal gyrus, the effect signified increased deactivation).

No other significant interactions between the ZNF804A and CACNA1C genotypes were found when inspecting the $\mathrm{BD}, \mathrm{SCZ}$ alone or all patients with a history of psychosis groups as a whole.

\subsubsection{ZNF $804 A$ by $C A C N A 1 C$ by diagnosis interaction}

There were significant 3-way interactions between the ZNF804A genotype, CACNAIC genotype and diagnosis (at voxel-level FWE $\mathrm{p}<0.05$; Table 1). The above genotype interaction effect significant in healthy subjects, was reversed in BD in the anterior cerebellum (vermis; $Z=4.56, \cdot{ }_{\mathrm{p}}^{2}=13.90 \%$ ), the $\mathrm{R}$ thalamus $(\mathrm{Z}=4.55$ and $\mathrm{Z}=4.37$; Figure 3 ) and both hemisphere caudate nucleus $(Z=4.52$ and $Z=4.46)$; and in SCZ in the $L$ superior $\left(\mathrm{Z}=4.65, \cdot{ }_{\mathrm{p}}^{2}=8.82 \%\right.$; Figure 3$)$ and middle $(\mathrm{Z}=4.55)$ temporal gyri. This means that, in their respective areas, in each patient group, the $C A C N A 1 C$ risk allele carriers activated more (which in the anterior cerebellum, for this task, signifies decreased deactivation) than non- 
risk allele homozygotes, in the ZNF804A risk allele homozygotes group, but the reverse was seen for ZNF804A non-risk allele carriers.

When comparing both patient groups, this genotype interaction effect was found, as trend $(\mathrm{k}<5)$, to be more pronounced in BD than in SCZ in the $\mathrm{R}$ medial caudate nucleus $(Z=4.20$, $\left.\cdot{ }_{\mathrm{p}}^{2}=10.24 \%\right)$.

The previous genotype interaction was also found, at trend level, to be more pronounced in patients with a history of psychosis than in controls in the $R$ anterior thalamus $(Z=4.20$, $\left.._{\mathrm{p}}^{2}=8.87 \%\right)$.

\subsection{Psycho-physiological interaction connectivity}

For the CACNAIC SNP, there was a significant (voxel-level FWE $\mathrm{p}<0.05$ ) genotype by diagnosis interaction in condition-specific connectivity between the seed region (L precentral gyrus/inferior frontal gyrus) and the $\mathrm{L}$ superior temporal gyrus $(\mathrm{Z}=5.07$; Figure 1$), \mathrm{L}$ middle temporal gyrus $(Z=4.80)$, whereby the risk allele carriers showed decreased connectivity versus non-risk allele homozygotes in SCZ, but not in controls (Table 1). In addition, this same interaction effect was found, as trend, in the L supramarginal gyrus $(Z=4.29)$, and, in the $\mathrm{SCZ}$ alone, in the $\mathrm{L}$ superior temporal gyrus $(\mathrm{Z}=4.36)$. Inspecting the control group alone, we found increased connectivity between the seed region and the $R$ precuneus $(Z=4.51)$. No significant epistatic effects, or of diagnosis, were found.

\subsection{Region-of-interest analysis}


No significant genotype effects were found at voxel-level FWE $\mathrm{p}<0.05$ when using either a mask using the pre-selected Brodmann areas or spheres to restrict the analysis to previously implicated brain areas in the published literature.

\subsection{Potentially confounding factors}

We found no variable to have an effect (at $\mathrm{p}<0.01$, uncorrected) on brain activation in areas that we report as being under a genotype effect. We also found no relevant change in effect size or foci of activation of genotype effects when these variables were introduced in the SPM ANOVA. Thirdly, no variable correlated with the peak activations values retrieved from our genotype effect analyses.

\subsection{Gene expression}

Using the Allen Brain Atlas, we found CACNA1C rs1006737 risk allele A to be associated with reduced mRNA levels of CACNA1C in total transcript levels ( $p>0.05$, FDR-corrected) in the cerebellum and trends for exon-specific probes in the cerebellum and white matter (Supplementary Table 6). CACNA1C enriched areas were identified in the thalamic nuclei, denteate gyrus, frontal and occipital poles. Detailed information is presented in supplementary material 6 .

\section{Discussion}

In summary, we assessed the main effect of CACNA1C rs1006737 genotype and, unprecedentedly, its epistatic interplay with ZNF804A rs1344706 - and whether these effects 
were altered in SCZ and BD groups - in regional brain activation and functional connectivity during verbal fluency - a task which engages brain regions and cognitive processes impaired in the two disorders. We found the CACNAIC genotype to modulate both brain activation and task-dependent effective connectivity - as assessed with PPI. We also found some of the genotype effect in some brain areas to be particularly pronounced in SCZ, BD or compared to health. In addition, we found an interaction effect of $C A C N A 1 C$ and $Z N F 804 A$ genotypes on regional brain activation.

We found $C A C N A 1 C$ rs1006737 SNP to be associated with inefficient activation (i.e. increased activation when only correct trials were analysed, as we did) in prefrontal regions, which are typically implicated in SZ and BD. The superior temporal gyri bilaterally, the $\mathrm{R}$ middle temporal gyrus, the L occipital gyrus (whether or not within the calcarine sulcus area), and the L lingual gyrus were under a significant genotype $\mathrm{x}$ diagnosis interaction, whereby the presence of the risk allele increased inefficient activation in BD patients much more than in controls. Furthermore, this same effect was present, as trend, in the L middle frontal gyrus and $\mathrm{R}$ angular gyrus. In fact, in most of these areas, the genotype effect was significant in BD alone. The same interaction effect was also found as trend when considering SCZ versus controls, in the adjacent $\mathrm{R}$ inferior frontal gyrus, pars opercularis. When all psychotic patients were grouped together against controls, the interaction effects survived in the L middle frontal gyrus and in the L occipital gyrus within the calcarine sulcus area.

Our above findings support previous studies implicating the same polymorphism in semantic verbal fluency (Krug et al. 2010) and working memory (Bigos et al. 2010) neural correlates (even though not consistently (Paulus et al. 2014)). However, while these studies showed this in healthy volunteers - not having tested a clinical population - we show it to be significantly 
stronger in $\mathrm{BD}$ and $\mathrm{SCZ}$, for the first time. As mentioned, given that task performance has been controlled for, increased activation in the risk genotype group could be interpreted as lower neuronal efficiency. This is compatible with the same observation of inefficiency, in an ill group, being found (as well as lower performance), for verbal fluency, in SCZ and, albeit less severely, of BD (Curtis et al. 2001, 2007; Costafreda et al. 2011; Gurung \& Prata 2015). The rationale is that once there is impaired prefrontal capacity (provided by a risk genotype or illness), additional activation of local neuronal resources may be needed in order to maintain a good-enough task performance. No areas showed the opposite effect, i.e., overactivation in the protective genotype group.

Sub-cortically, the thalamus showed greater activation, bilaterally (albeit as a trend in the L thalamus), in risk allele carriers, irrespective of diagnosis (with the effect in the R thalamus also being significant in BD patients on their own). The thalamus plays a critical role in the coordination of information as it passes between several brain regions (Kruger 1986). A disruption of that information flow may give rise to some of the cardinal symptoms of SCZ and BD (Cronenwett \& Csernansky 2010), as suggested by previous studies showing: 1) altered thalamic volumes in BD and SCZ patients (Radenbach et al. 2010; Smith et al. 2011); 2) reduced neuronal density in post-mortem thalamic samples of SCZ patients (Blennow et al. 1996); 3) altered thalamic glutamate receptor expression and elevated dopamine in thalamic sub-regions (Meador-Woodruff et al. 2003); 4) emergence of SCZ-like syndromes when illnesses, such as stroke, selectively damage the thalamus while sparing the rest of the brain (Crail-Melendez et al. 2013).

We also report, for the first time, CACNA1C and ZNF804A epistases on brain activation. We predicted, and found, that their respective GWAs-implicated SNPs would interact in an 
additive manner, with the most inefficient activation occurring when both risk alleles were present (compared to just one or the other being present). This interaction effect was also significantly stronger in the SCZ and BD groups when contrasted individually against the control group. In SCZ, this was seen in the L superior and middle temporal gyrus and in BD, in the anterior cerebellum (vermis), the $\mathrm{R}$ thalamus and the caudate nucleus (an area specifically implicated in psychosis (Hannan et al. 2010)). When the psychotic patients were contrasted against controls, the epistatic effect was stronger, at trend level, in the R anterior thalamus.

The abnormal thalamic responses above are quite consistent with thalamus-based explanations for the 'cognitive dysmetria' of SCZ that has been proposed to underlie cognitive and fluency effects in the illness (Andreasen et al. 1998); cognitive dysmetria being a special case of functional dysconnection. On a more general note, our results speak to the disconnection hypothesis of SCZ (Friston et al. 2016) at a number of levels. First, the polymorphisms we have shown to affect condition-specific connectivity affect the regulation of synaptic efficacy (and plasticity) thought to underlie the dysfunctional integration in syndromes like SCZ. In brief, these aberrant (usually inefficient, disinhibited) responses to (cognitive) task-induced processes are thought to reflect a failure of gain control, synaptic excitation inhibition balance or, in the context of predictive coding, precision control in hierarchical message passing in the brain.

In line with the caudate nucleus being especially implicated in positive symptoms of psychosis, we found this area to show an additive effect of the risk alleles, which was stronger in $\mathrm{SCZ}$ than $\mathrm{BD}$ in the $\mathrm{R}$ caudate nucleus at trend level. This region belongs to the 
striatum, which has been repeatedly implicated in the positive (i.e. psychotic) symptoms of SCZ (Laruelle \& Abi-Dargham 1999; Kirschner et al. 2018) and with abnormal dopamine levels (Laruelle \& Abi-Dargham 1999; Breier et al. 1997; Abi-Dargham et al. 1998; Laruelle et al. 1999). These findings are consistent with the hypothesis that both these polymorphisms increase risk for psychosis. The two-SNP additive interaction was not seen independently of diagnosis, nor was the opposite direction of effect seen anywhere in the brain. The former suggests that the existence of other factors specific to SCZ, BD or psychosis make subjects more susceptible to the potential detrimental effects on brain function of the simultaneous presence of both the risk variants of these genome-wide associated polymorphisms.

In terms of task-specific effects on connectivity, we have also found a significant genotype by diagnosis interaction: the risk allele was associated with an intra-hemispheric connectivity decrease between the $\mathrm{L}$ precentral gyrus/inferior frontal gyrus, pars opercularis and the ipsilateral superior temporal gyrus, middle temporal gyrus and supramarginal (as trend) gyrus in SCZ but not in controls. In the first area, the decrease was indeed found as a trend in SCZ alone. These cortical effects are particularly consistent with our recent results showing this risk variant to be associated with decreased microstructural white matter integrity also in the L inferior and superior temporal gyri, and also found in SCZ only (Mallas et al. 2016a). Further support comes as well from reduced white matter integrity findings from others, also specifically in SCZ patients and in the same hemisphere and cortical areas: L temporal lobe (Woon et al. 2014) (more precisely in the L inferior and superior temporal gyrus (Mallas et al. 2016a)) and L parietal lobe (Woon et al. 2014). Our results are also consistent with previous independent findings in emotional face processing whereby the risk allele is 
associated with amygdalar functional connectivity with the $\mathrm{L}$ fronto-temporal areas (Wang et al. 2011).

Importantly, the above effects on functional and structural connectivity are further consistent with our gene expression findings: a novel association of the $C A C N A 1 C$ rs 1006737 risk allele with reduced mRNA levels of CACNA1C in white matter. This has also been independently found in the superior temporal gyrus (Eckart et al. 2016), an area typically affected in BD and SCZ (Ratnanather et al. 2013). Nevertheless, other studies with the dorsolateral prefrontal cortex (Bigos et al. 2010) and human induced-neurons (Yoshimizu et al. 2015), suggest the risk allele may also increase CACNA1C transcription at least in other areas - which may reflect a very finely tuned regulation of this gene in the brain.

The risk allele association with reduced gene expression was also found in the cerebellum which is a direct replication of a previous independent work (Gershon et al. 2014). Indeed, we found this area to be recruited in 'verbal fluency' compared to 'repetition' (control) trials (Tecelão et al. 2018), as has been implicated by others using this task (Peterburs et al. 2010). Further studies using specific cerebellum-recruiting paradigms (i.e. sensorimotor tasks) will allow a clearer examination of this polymorphism's impact on cerebellar function.

Finally, we provide a brain region- and structure-based map of CACNA1C mRNA distribution in the human brain. We identified the thalamic nuclei, the dentate gyrus, and the frontal and occipital poles as areas enriched in CACNA1C mRNA expression. Although limited by the possible discordance between mRNA and protein levels, this is the most detailed map so far published of the putative distribution of CACNA1C in the human brain. The data gathered may improve the interpretation of both future pharmaco-imaging and imaging genetics endeavours exploring the role of this channel in the human brain, based on 
the fact that if positive findings could be achieved it is more likely that they appear in areas where the channel is most expressed and presumably more important from a functional point of view.

As a limitation of our ANOVA interaction tests, we note that the size in each of the smallest homogeneous groups (or "cells" in the parametric design matrix) which combine the diagnostic group, the ZNF804A rs1344706 and the CACNAIC rs1006737 genotype, is modest, albeit the vast majority (10 in 12 groups) is over 10 subjects and up to 26 subjects (see Materials and Methods). Although the sample size we used herein compares well with that of contemporary functional imaging genetic studies of these and other SCZ- and BD-risk polymorphisms (Gurung \& Prata 2015), we recommend future independent and metaanalytical evidence is gathered to confirm these genes' role, and their interplay, at the systems brain level.

\section{Conclusions}

We have shown an effect of $C A C N A 1 C$ rs1006737 on brain activation, task-dependent functional connectivity and gene expression. We have also found unprecedented evidence of epistasis of $C A C N A 1 C$ and $Z N F 804 A$ genotypes on brain activation during verbal fluency. Several of these effects were highly dependent on both BD or SCZ diagnosis. Taken together, our results support genetic and neuroimaging genetics evidence implicating $C A C N A 1 C$ and ZNF804A polymorphisms in $\mathrm{BD}$ and SCZ. Although current evidence on the clinical efficacy of calcium channels blockers in the treatment of psychosis (i.e. BD mania) is insufficient to support its use in the clinical practice (Levy \& Janicak 2000), further studies scrutinizing the neurobiological mechanisms by which dysregulation of $C A C N A 1 C$ may 
affect neuronal function and, as such, increase the risk for psychosis should be encouraged. These studies will be critical for our understanding of the pathophysiological mechanisms of these disorders and, from there, putatively derive new drug targets to improve their clinical management.

\section{Acknowledgments}

DP was supported by a UK National Institute for Health Research fellowship (NIHR, PDF2010-03-047), a Marie Curie Career Integration grant (FP7-PEOPLE-2013-CIG- 631952) and a Fundação para Ciência e Tecnologia (FCT) Investigator grant (IF/00787/2014), and a Bial Foundation Grant (2016). DM was supported by an FCT PhD fellowship (PD/BD/114098/2015) and a joint award from AstraZeneca and the Faculty of Medicine of

This article is protected by copyright. All rights reserved. 
the University of Lisbon. EB was supported by a Medical Research Council (MRC) New Investigator Award (G0901310) and the Wellcome Trust (085475/B/08/Z and 085475/Z/08/Z). This work was also supported by the British Research Council (BRC). None of the authors declare any conflict of interest.

This article is protected by copyright. All rights reserved. 


\section{References}

Abi-Dargham, A., Gil, R., Krystal, J., Baldwin, R.M., Seibyl, J.P., Bowers, M., van Dyck, C.H., Charney, D.S., Innis, R.B. \& Laruelle, M. (1998) Increased striatal dopamine transmission in schizophrenia: confirmation in a second cohort. Am J Psychiatry 155, $761-767$.

American Psychiatric Association. (1994) Diagnostic and statistical manual of mental disorders: DSM-IV. American Psychiatric Association, Washington, DC.

Andreasen, N.C., Paradiso, S. \& O’Leary, D.S. (1998) "Cognitive Dysmetria” as an Integrative Theory of Schizophrenia: A Dysfunction in Cortical-SubcorticalCerebellar Circuitry? Schizophr Bull 24, 203-218.

Bigos, K.L., Mattay, V.S., Callicott, J.H., Straub, R.E., Vakkalanka, R., Kolachana, B., Hyde, T.M., Lipska, B.K., Kleinman, J.E. \& Weinberger, D.R. (2010) Genetic Variation in CACNA1C Affects Brain Circuitries Related to Mental Illness. Arch Gen Psychiatry 67, 939-945.

Blennow, K., Davidsson, P., Gottfries, C.-G., Ekman, R. \& Heilig, M. (1996) Synaptic degeneration in thalamus in schizophrenia. The Lancet 348, 692-693.

Booij, L., Van der Does, A.J.W. \& Riedel, W.J. (2003) Monoamine depletion in psychiatric and healthy populations: review. Mol Psychiatry 8, 951-973.

This article is protected by copyright. All rights reserved. 
Breier, A., Su, T.-P., Saunders, R., Carson, R.E., Kolachana, B.S., De Bartolomeis, A., Weinberger, D.R., Weisenfeld, N., Malhotra, A.K., Eckelman, W.C. \& others. (1997) Schizophrenia is associated with elevated amphetamine-induced synaptic dopamine concentrations: evidence from a novel positron emission tomography method. Proc Natl Acad Sci 94, 2569-2574.

Bryois, J., Buil, A., Evans, D.M., Kemp, J.P., Montgomery, S.B., Conrad, D.F., Ho, K.M., Ring, S., Hurles, M., Deloukas, P., Davey Smith, G. \& Dermitzakis, E.T. (2014) Cis and Trans Effects of Human Genomic Variants on Gene Expression. PLoS Genet 10, e1004461.

Cardno, A.G., Marshall, E.J., Coid, B., MacDonald, A.M., Ribchester, T.R., Davies, N.J., Venturi, P., Jones, L.A., Lewis, S.W., Sham, P.C., Gottesman, I.I., Farmer, A.E., McGuffin, P., Reveley, A.M. \& Murray, R.M. (1999) Heritability estimates for psychotic disorders: the Maudsley twin psychosis series. Arch Gen Psychiatry 56, $162-168$.

Costafreda, S.G., Fu, C.H., Picchioni, M., Toulopoulou, T., McDonald, C., Kravariti, E., Walshe, M., Prata, D., Murray, R.M. \& McGuire, P.K. (2011) Pattern of neural responses to verbal fluency shows diagnostic specificity for schizophrenia and bipolar disorder. BMC Psychiatry 1, 1-10.

Crail-Melendez, D., Atriano-Mendieta, C., Carrillo-Meza, R. \& Ramirez-Bermudez, J. (2013) Schizophrenia-like psychosis associated with right lacunar thalamic infarct. Neurocase 19, 22-26.

This article is protected by copyright. All rights reserved. 
Cronenwett, W.J. \& Csernansky, J. (2010) Thalamic Pathology in Schizophrenia. In Swerdlow, N.R. (ed), Behavioral Neurobiology of Schizophrenia and Its Treatment, Springer Berlin Heidelberg, Berlin, Heidelberg, pp. 509-528.

Curtis, V.A., Bullmore, E.T., Brammer, M.J., Wright, I.C., Williams, S.C., Morris, R.G., Sharma, T.S., Murray, R.M. \& McGuire, P.K. (1998) Attenuated frontal activation during a verbal fluency task in patients with schizophrenia. Am J Psychiatry 155, $1056-1063$.

Curtis, V.A., Bullmore, E.T., Morris, R.G., Brammer, M.J., Williams, S.C., Simmons, A., Sharma, T., Murray, R.M. \& McGuire, P.K. (1999) Attenuated frontal activation in schizophrenia may be task dependent. Schizophr Res 37, 35-44.

Curtis, V.A., Dixon, T.A., Morris, R.G., Bullmore, E.T., Brammer, M.J., Williams, S.C.R., Sharma, T., Murray, R.M. \& McGuire, P.K. (2001) Differential frontal activation in schizophrenia and bipolar illness during verbal fluency. J Affect Disord 66, 111-121.

Curtis, V.A., Thompson, J.M., Seal, M.L., Monks, P.J., Lloyd, A.J., Harrison, L., Brammer, M.J., Williams, S.C., Murray, R.M., Young, A.H. \& others. (2007) The nature of abnormal language processing in euthymic bipolar I disorder: evidence for a relationship between task demand and prefrontal function. Bipolar Disord 9, 358369.

This article is protected by copyright. All rights reserved. 
Daban, C., Martinez-Aran, A., Torrent, C., Tabarés-Seisdedos, R., Balanzá-Martínez, V., Salazar-Fraile, J., Selva-Vera, G. \& Vieta, E. (2006) Specificity of Cognitive Deficits in Bipolar Disorder versus Schizophrenia. Psychother Psychosom 75, 72-84.

Dietsche, B., Backes, H., Laneri, D., Weikert, T., Witt, S.H., Rietschel, M., Sommer, J., Kircher, T. \& Krug, A. (2014) The impact of a CACNA1C gene polymorphism on learning and hippocampal formation in healthy individuals: A diffusion tensor imaging study. NeuroImage 89, 256-261.

Eckart, N., Song, Q., Yang, R., Wang, R., Zhu, H., McCallion, A.S. \& Avramopoulos, D. (2016) Functional Characterization of Schizophrenia-Associated Variation in CACNA1C. PLOS ONE 11, e 0157086.

Ferreira, M.A.R., O’Donovan, M.C., Meng, Y.A., Jones, I.R., Ruderfer, D.M., Jones, L., Fan, J., Kirov, G., Perlis, R.H., Green, E.K., Smoller, J.W., Grozeva, D., Stone, J., Nikolov, I., Chambert, K., Hamshere, M.L., Nimgaonkar, V.L., Moskvina, V., Thase, M.E., Caesar, S., Sachs, G.S., Franklin, J., Gordon-Smith, K., Ardlie, K.G., Gabriel, S.B., Fraser, C., Blumenstiel, B., Defelice, M., Breen, G., Gill, M., Morris, D.W., Elkin, A., Muir, W.J., McGhee, K.A., Williamson, R., MacIntyre, D.J., MacLean, A.W., St Clair, D., Robinson, M., Van Beck, M., Pereira, A.C.P., Kandaswamy, R., McQuillin, A., Collier, D.A., Bass, N.J., Young, A.H., Lawrence, J., Nicol Ferrier, I., Anjorin, A., Farmer, A., Curtis, D., Scolnick, E.M., McGuffin, P., Daly, M.J., Corvin, A.P., Holmans, P.A., Blackwood, D.H., Gurling, H.M., Owen, M.J., Purcell, S.M., Sklar, P. \& Craddock, N. (2008) Collaborative genome-wide association analysis 
supports a role for ANK3 and CACNA1C in bipolar disorder. Nat Genet 40, 10561058.

Franke, B., Vasquez, A.A., Veltman, J.A., Brunner, H.G., Rijpkema, M. \& Fernández, G. (2010) Genetic Variation in CACNA1C, a Gene Associated with Bipolar Disorder, Influences Brainstem Rather than Gray Matter Volume in Healthy Individuals. Biol Psychiatry 68, 586-588.

Frazier, T.W., Youngstrom, E.A., Frankel, B.A., Zunta-Soares, G.B., Sanches, M., Escamilla, M., Nielsen, D.A. \& Soares, J.C. (2014) Candidate gene associations with mood disorder, cognitive vulnerability, and fronto-limbic volumes. Brain Behav 4, 418-430.

Friston, K., Brown, H.R., Siemerkus, J. \& Stephan, K.E. (2016) The dysconnection hypothesis (2016). Schizophr Res 176, 83-94.

Fu, C.H.Y., Morgan, K., Suckling, J., Williams, S.C.R., Andrew, C., Vythelingum, G.N. \& McGuire, P.K. (2002) A Functional Magnetic Resonance Imaging Study of Overt Letter Verbal Fluency Using a Clustered Acquisition Sequence: Greater Anterior Cingulate Activation with Increased Task Demand. NeuroImage 17, 871-879.

Fu, C.H.Y., Suckling, J., Williams, S.C.R., Andrew, C.M., Vythelingum, G.N. \& McGuire, P.K. (2005) Effects of Psychotic State and Task Demand on Prefrontal Function in Schizophrenia: An fMRI Study of Overt Verbal Fluency. Am J Psychiatry 162, 485494.

This article is protected by copyright. All rights reserved. 
Gershon, E.S., Grennan, K., Busnello, J., Badner, J.A., Ovsiew, F., Memon, S., AllieyRodriguez, N., Cooper, J., Romanos, B. \& Liu, C. (2014) A rare mutation of CACNA1C in a patient with bipolar disorder, and decreased gene expression associated with a bipolar-associated common SNP of CACNA1C in brain. Mol Psychiatry 19, 890-894.

Green, E.K., Grozeva, D., Jones, I., Jones, L., Kirov, G., Caesar, S., Gordon-Smith, K., Fraser, C., Forty, L., Russell, E. \& others. (2010) The bipolar disorder risk allele at CACNA1C also confers risk of recurrent major depression and of schizophrenia. Mol Psychiatry 15, 1016-1022.

Gurung, R. \& Prata, D.P. (2015) What is the impact of genome-wide supported risk variants for schizophrenia and bipolar disorder on brain structure and function? A systematic review. Psychol Med 45, 2461-2480.

Hannan, K.L., Wood, S.J., Yung, A.R., Velakoulis, D., Phillips, L.J., Soulsby, B., Berger, G., McGorry, P.D. \& Pantelis, C. (2010) Caudate nucleus volume in individuals at ultrahigh risk of psychosis: A cross-sectional magnetic resonance imaging study. Psychiatry Res Neuroimaging 182, 223-230.

K. Mai, J., Paxinos, G. \& Voss, T. (2008) Atlas of the Human Brain, 3rd Edition. 3rd edn. Academic Press, San Diego.

This article is protected by copyright. All rights reserved. 
Kempton, M.J., Gaia, R., Vassos, E., Tatarelli, R., Girardi, P., Collier, D. \& Frangou, S. (2009) Effects of the CACNA1C risk allele for bipolar disorder on cerebral gray matter volume in healthy individuals. Am J Psychiatry 166, 1413-1414.

Kieseppä, T., Partonen, T., Haukka, J., Kaprio, J. \& Lönnqvist, J. (2004) High Concordance of Bipolar I Disorder in a Nationwide Sample of Twins. Am J Psychiatry 161, 18141821.

Kirschner, M., Hager, O.M., Muff, L., Bischof, M., Hartmann-Riemer, M.N., Kluge, A., Habermeyer, B., Seifritz, E., Tobler, P.N. \& Kaiser, S. (2018) Ventral Striatal Dysfunction and Symptom Expression in Individuals With Schizotypal Personality Traits and Early Psychosis. Schizophr Bull 44, 147-157.

Krabbendam, L., Arts, B., van Os, J. \& Aleman, A. (2005) Cognitive functioning in patients with schizophrenia and bipolar disorder: A quantitative review. Schizophr Res 80, $137-149$.

Krug, A., Nieratschker, V., Markov, V., Krach, S., Jansen, A., Zerres, K., Eggermann, T., Stöcker, T., Shah, N.J., Treutlein, J., Mühleisen, T.W. \& Kircher, T. (2010) Effect of CACNA1C rs1006737 on neural correlates of verbal fluency in healthy individuals. NeuroImage 49, 1831-1836.

Kruger, L. (1986) Neuroanatomy: the thalamus., Science 232, 1028-9.

Lancaster, J.L., Summerlin, J.L., Rainey, L., Freitas, C.S. \& Fox, P.T. (1997) The Talairach Daemon, a database server for talairach atlas labels. NeuroImage 5.

This article is protected by copyright. All rights reserved. 
Lancaster, J.L., Woldorff, M.G., Parsons, L.M., Liotti, M., Freitas, C.S., Rainey, L., Kochunov, P.V., Nickerson, D., Mikiten, S.A. \& Fox, P.T. (2000) Automated Talairach atlas labels for functional brain mapping. Hum Brain Mapp 10, 120-131.

Laruelle, M. \& Abi-Dargham, A. (1999) Dopamine as the wind of the psychotic fire: new evidence from brain imaging studies. J Psychopharmacol (Oxf) 13, 358-371.

Laruelle, M., Abi-Dargham, A., Gil, R., Kegeles, L. \& Innis, R. (1999) Increased dopamine transmission in schizophrenia: relationship to illness phases. Biol Psychiatry 46, 5672.

Levy, N.A. \& Janicak, P.G. (2000) Calcium channel antagonists for the treatment of bipolar disorder. Bipolar Disord 2, 108-119.

Maldjian, J.A., Laurienti, P.J., Kraft, R.A. \& Burdette, J.H. (2003) An automated method for neuroanatomic and cytoarchitectonic atlas-based interrogation of fMRI data sets. NeuroImage 19, 1233-1239.

Mallas, E.-J., Carletti, F., Chaddock, C.A., Shergill, S., Woolley, J., Picchioni, M.M., McDonald, C., Toulopoulou, T., Kravariti, E., Kalidindi, S., Bramon, E., Murray, R., Barker, G.J. \& Prata, D.P. (2016a) The impact of CACNA1C gene, and its epistasis with ZNF804A, on white matter microstructure in health, schizophrenia and bipolar disorder. Genes Brain Behav.

Mallas, E.-J., Carletti, F., Chaddock, C.A., Woolley, J., Picchioni, M.M., Shergill, S.S., Kane, F., Allin, M.P.G., Barker, G.J. \& Prata, D.P. (2016b) Genome-wide discovered 
psychosis-risk gene ZNF804A impacts on white matter microstructure in health, schizophrenia and bipolar disorder. PeerJ 4, e1570.

Meador-Woodruff, J.H., Clinton, S.M., Beneyto, M. \& McCullumsmith, R.E. (2003) Molecular Abnormalities of the Glutamate Synapse in the Thalamus in Schizophrenia. Ann N Y Acad Sci 1003, 75-93.

Mechelli, A., Prata, D.P., Fu, C.H.Y., Picchioni, M., Kane, F., Kalidindi, S., McDonald, C., Demjaha, A., Kravariti, E., Toulopoulou, T., Murray, R., Collier, D.A. \& McGuire, P.K. (2008) The effects of neuregulin1 on brain function in controls and patients with schizophrenia and bipolar disorder. NeuroImage 42, 817-826.

Nyegaard, M., Demontis, D., Foldager, L., Hedemand, A., Flint, T.J., Sørensen, K.M., Andersen, P.S., Nordentoft, M., Werge, T., Pedersen, C.B., Hougaard, D.M., Mortensen, P.B., Mors, O. \& Børglum, A.D. (2010) CACNA1C (rs1006737) is associated with schizophrenia. Mol Psychiatry 15, 119-121.

Paulus, F.M., Bedenbender, J., Krach, S., Pyka, M., Krug, A., Sommer, J., Mette, M., Nöthen, M.M., Witt, S.H., Rietschel, M., Kircher, T. \& Jansen, A. (2014) Association of rs1006737 in CACNA1C with alterations in prefrontal activation and frontohippocampal connectivity: CACNA1C rs1006737 Effects on Prefrontal Functioning. Hum Brain Mapp 35, 1190-1200.

This article is protected by copyright. All rights reserved. 
Peterburs, J., Bellebaum, C., Koch, B., Schwarz, M. \& Daum, I. (2010) Working Memory and Verbal Fluency Deficits Following Cerebellar Lesions: Relation to Interindividual Differences in Patient Variables. The Cerebellum 9, 375-383.

Prata, D.P., Mechelli, A., Fu, C.H.Y., Picchioni, M., Kane, F., Kalidindi, S., McDonald, C., Howes, O., Kravariti, E., Demjaha, A., Toulopoulou, T., Diforti, M., Murray, R.M., Collier, D.A. \& McGuire, P.K. (2009a) Opposite Effects of Catechol-OMethyltransferase Val158Met on Cortical Function in Healthy Subjects and Patients with Schizophrenia. Biol Psychiatry 65, 473-480.

Prata, D.P., Mechelli, A., Picchioni, M.M., Fu, C.H., Toulopoulou, T., Bramon, E., Walshe, M., Murray, R.M., Collier, D.A. \& McGuire, P. (2009b) Altered effect of dopamine transporter 32 UTR VNTR genotype on prefrontal and striatal function in schizophrenia. Arch Gen Psychiatry 66, 1162-1172.

R Core Team. (2016) R: A language and environment for statistical computing. R Foundation for Statistical Computing, Vienna, Austria.

Radenbach, K., Flaig, V., Schneider-Axmann, T., Usher, J., Reith, W., Falkai, P., Gruber, O. \& Scherk, H. (2010) Thalamic volumes in patients with bipolar disorder. Eur Arch Psychiatry Clin Neurosci 260, 601-607.

Ramasamy, A., Trabzuni, D., Guelfi, S., Varghese, V., Smith, C., Walker, R., De, T., Hardy, J., Ryten, M., Trabzuni, D., Guelfi, S., Weale, M.E., Ramasamy, A., Forabosco, P., Smith, C., Walker, R., Arepalli, S., Cookson, M.R., Dillman, A., Gibbs, J.R., 
Hernandez, D.G., Nalls, M.A., Singleton, A.B., Traynor, B., van der Brug, M., Ferrucci, L., Johnson, R., Zielke, R., Longo, D.L., Troncoso, J., Zonderman, A., Coin, L., de Silva, R., Cookson, M.R., Singleton, A.B., Hardy, J., Ryten, M. \& Weale, M.E. (2014) Genetic variability in the regulation of gene expression in ten regions of the human brain. Nat Neurosci 17, 1418-1428.

Ratnanather, J.T., Poynton, C.B., Pisano, D.V., Crocker, B., Postell, E., Cebron, S., Ceyhan, E., Honeycutt, N.A., Mahon, P.B. \& Barta, P.E. (2013) Morphometry of superior temporal gyrus and planum temporale in schizophrenia and psychotic bipolar disorder. Schizophr Res 150, 476-483.

Smith, M.J., Wang, L., Cronenwett, W., Mamah, D., Barch, D.M. \& Csernansky, J.G. (2011) Thalamic morphology in schizophrenia and schizoaffective disorder. J Psychiatr Res 45, 378-385.

Tecelão, D., Mendes, A., Martins, D., Bramon, E., Toulopoulou, T., Kravariti, E., Murray, R. \& Prata, D. (2018) The impact of psychosis genome-wide associated ZNF804A variation on verbal fluency connectivity. J Psychiatr Res 98, 17-21.

Tzourio-Mazoyer, N., Landeau, B., Papathanassiou, D., Crivello, F., Etard, O., Delcroix, N., Mazoyer, B. \& Joliot, M. (2002) Automated Anatomical Labeling of Activations in SPM Using a Macroscopic Anatomical Parcellation of the MNI MRI Single-Subject Brain. NeuroImage 15, 273-289.

This article is protected by copyright. All rights reserved. 
Uemura, T., Green, M. \& Warsh, J.J. (2015) CACNA1C SNP rs1006737 associates with bipolar I disorder independent of the Bcl-2 SNP rs956572 variant and its associated effect on intracellular calcium homeostasis. World J Biol Psychiatry 1-10.

Wang, F., McIntosh, A.M., He, Y., Gelernter, J. \& Blumberg, H.P. (2011) The association of genetic variation in CACNA1C with structure and function of a frontotemporal system: Frontotemporal effects of CACNA1C. Bipolar Disord 13, 696-700.

Woon, P.S., Sum, M.Y., Kuswanto, C.N., Yang, G.L., Sitoh, Y.Y., Soong, T.W., Lee, T.S., Nowinski, W.L. \& Sim, K. (2014) CACNA1C genomewide supported psychosis genetic variation affects cortical brain white matter integrity in Chinese patients with schizophrenia. J Clin Psychiatry 75, e1284-1290.

Yoshimizu, T., Pan, J.Q., Mungenast, A.E., Madison, J.M., Su, S., Ketterman, J., Ongur, D., McPhie, D., Cohen, B., Perlis, R. \& Tsai, L.-H. (2015) Functional implications of a psychiatric risk variant within CACNA1C in induced human neurons. Mol Psychiatry 20, 162-169.

This article is protected by copyright. All rights reserved. 


\section{Figure legends}

Figure 1 - Effects on "verbal fluency > repetition" brain activation (Part A) and on psychophysiological interaction (PPI, i.e. task-dependent effective connectivity) with the seed L precentral gyrus/inferior frontal gyrus, pars opercularis (Part B) (the area most recruited for verbal fluency) at whole-brain voxel-level FWE $\mathrm{p}<0.05$. Part A: Main effect of $C A C N A 1 C$ rs1006737 genotype in the L Middle frontal gyrus (plotted), where risk allele (A) carriers

This article is protected by copyright. All rights reserved. 
activated more than $G$ homozygotes, particularly so in BD patients. Part B: Interaction of CACNA1C rs1006737 genotype and SCZ diagnosis on PPI, where the risk allele A carriers show decreased connectivity between the seed and L superior and middle temporal gyrus (plotted) in SCZ patients but the opposite in healthy controls.

Figure 2 - Interaction of $C A C N A 1 C$ rs1006737 genotype with diagnosis on "verbal fluency > repetition" brain activation, where the risk allele (A) was associated, at whole-brain voxellevel FWE $\mathrm{p}<0.05$, with increased activation in BD patients but the opposite in healthy controls, in the L superior temporal gyrus (plotted) as well as in its R homologue.

Figure 3 - Three-way interactions between the ZNF804A rs1344706, CACNA1C rs1006737 genotype and diagnosis on "verbal fluency > repetition" activation. Among the CACNAIC risk allele (A) carriers, $Z N F 804 A$ risk allele A homozygotes activated more than their counterparts, whereas the opposite applied in $C A C N A 1 C$ non-risk allele $(\mathrm{G})$ homozygotes, at whole-brain voxel-wise FWE $\mathrm{p}<0.05$. Part A: Interaction, where BD and controls were contrasted, in the R thalamus (plotted) and caudate nucleus bilaterally. Part B: Interaction, where SCZ and controls were contrasted, in the L superior and middle temporal gyrus (plotted). 
Main effect of CACNA1C rs1006737 genotype on regional brain activation
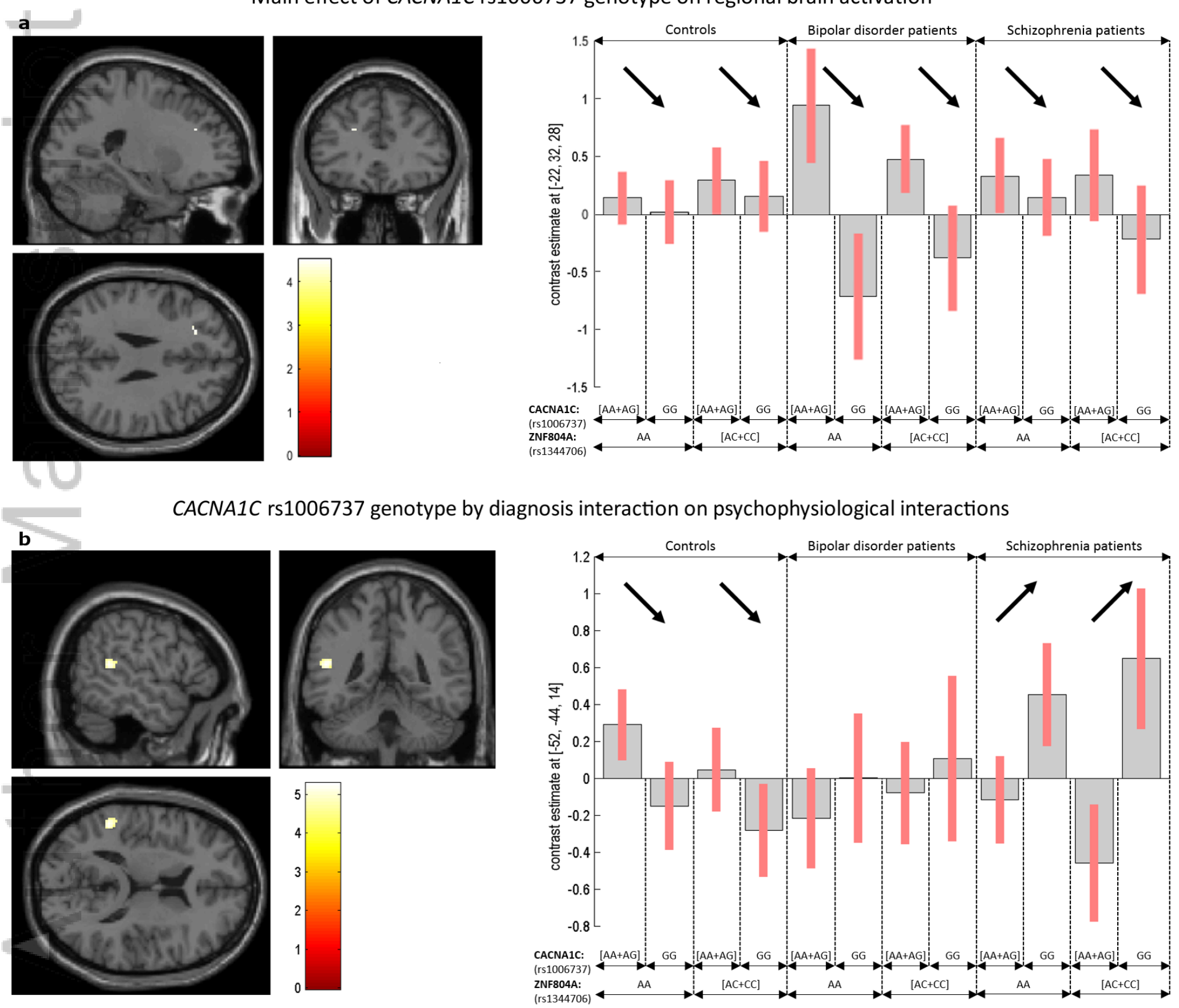

Figure 1.tif 
CACNA1C rs1006737 genotype by diagnosis interaction on regional brain activation
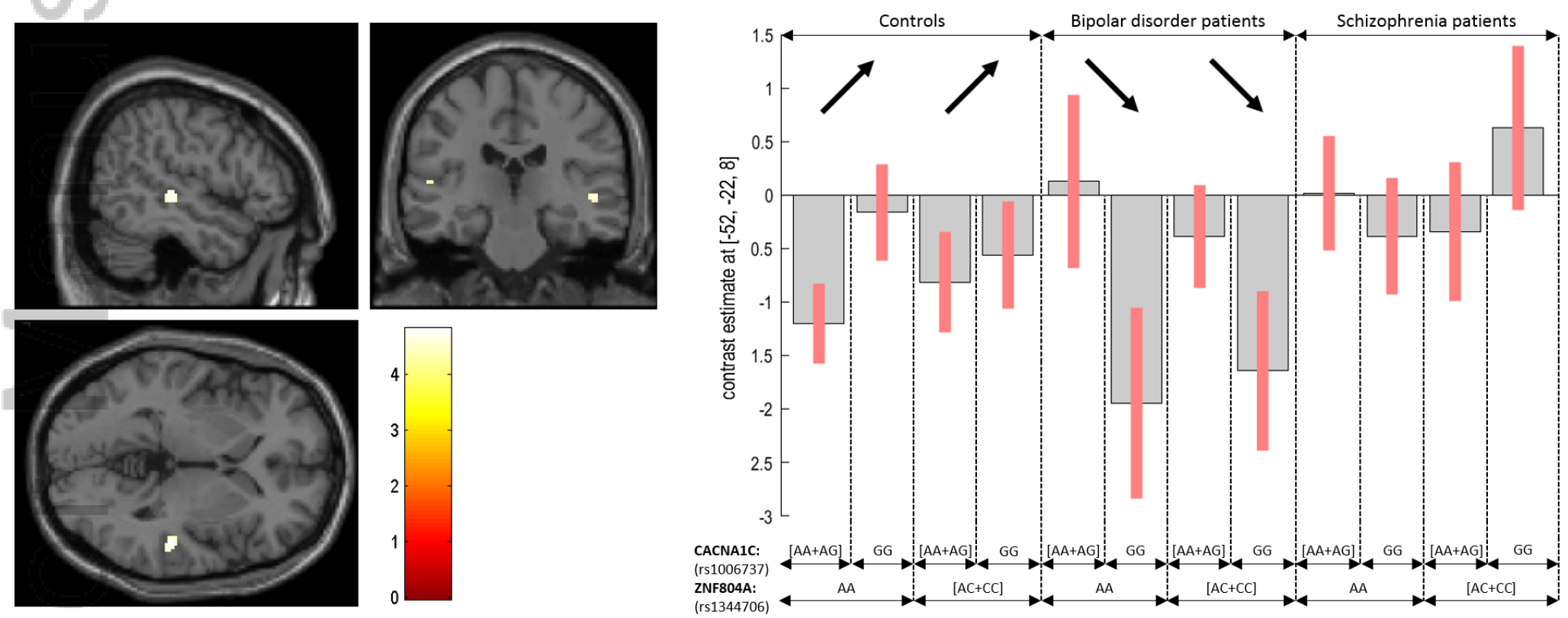

Figure 2.tif 
Table 1 - Regions under an effect of CACNA1C rs1006737, the risk allele being allele A. All inferences correspond to results corrected for whole-brain voxel-wise FWE multiple comparisons correction at $\mathrm{p}<0.05$. Cluster size $(\mathrm{k})$ is given only for the peak of each cluster.

\section{Regional activations}

\subsection{Effect of $C A C N A 1 C$ genotype}

\begin{tabular}{|c|c|c|c|}
\hline Contrasts & Regions & 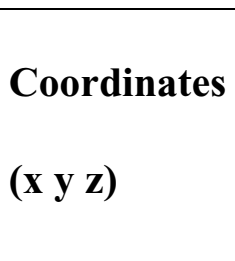 & $\begin{array}{l}\text { Z-score }(Z) \text {, voxel-wise } \\
\text { FWE corrected p-value } \\
(p), \text { cluster size }(k)\end{array}$ \\
\hline \multirow{3}{*}{$\mathrm{AA}+\mathrm{AG}>\mathrm{GG}$} & R Thalamus & $24-160$ & $\mathrm{Z}=4.44, \mathrm{p}=0.019, \mathrm{k}=8$ \\
\hline & L Middle frontal gyrus & $-223228^{a}$ & $\mathrm{Z}=4.32, \mathrm{p}=0.031, \mathrm{k}=5$ \\
\hline & L Thalamus ${ }^{*}$ & $-14-8-6^{a}$ & $\mathrm{Z}=4.27, \mathrm{p}=0.038, \mathrm{k}=1$ \\
\hline \multirow{9}{*}{$\begin{array}{l}\mathrm{AA}+\mathrm{AG}>\mathrm{GG} \\
\text { in } \mathrm{BD}\end{array}$} & R Thalamus & $24-162$ & $\mathrm{Z}=4.89, \mathrm{p}=0.003, \mathrm{k}=50$ \\
\hline & \multirow[t]{2}{*}{ L Middle frontal gyrus } & $-262630^{a}$ & $\mathrm{Z}=4.71, \mathrm{p}=0.007, \mathrm{k}=25$ \\
\hline & & $-284022^{*, a}$ & $\mathrm{Z}=4.21, \mathrm{p}=0.047, \mathrm{k}=3$ \\
\hline & L Superior frontal gyrus & $-183228^{a}$ & $\mathrm{Z}=4.56, \mathrm{p}=0.012$ \\
\hline & R Superior temporal gyrus & $52-28-2$ & $\mathrm{Z}=4.53, \mathrm{p}=0.014, \mathrm{k}=28$ \\
\hline & \multirow{2}{*}{ R Middle temporal gyrus } & $52-30-2$ & $\mathrm{Z}=4.47, \mathrm{p}=0.017$ \\
\hline & & $42-4820^{\mathrm{a}, \mathrm{b}}$ & $\mathrm{Z}=4.25, \mathrm{p}=0.041, \mathrm{k}=7$ \\
\hline & \multirow{2}{*}{$\begin{array}{l}\text { L Calcarine sulcus } \\
\text { (occipital gyrus) }^{*}\end{array}$} & $2-78-6$ & $\mathrm{Z}=4.28, \mathrm{p}=0.037, \mathrm{k}=2$ \\
\hline & & $-2-9610$ & $\mathrm{Z}=4.22, \mathrm{p}=0.046, \mathrm{k}=2$ \\
\hline \multirow{3}{*}{$\begin{array}{l}(\mathrm{AA}+\mathrm{AG}> \\
\mathrm{GG}) \&(\mathrm{BD}> \\
\mathrm{CON})\end{array}$} & R Superior temporal gyrus & $50-26-2^{a}$ & $\mathrm{Z}=4.72, \mathrm{p}=0.006, \mathrm{k}=49$ \\
\hline & R Middle temporal gyrus & $52-28-4$ & $\mathrm{Z}=4.53$ \\
\hline & L Superior temporal gyrus & $-52-228$ & $\mathrm{Z}=4.29, \mathrm{p}=0.036, \mathrm{k}=6$ \\
\hline
\end{tabular}




\begin{tabular}{|c|c|c|c|}
\hline & L Occipital gyrus & $-2-968$ & $\mathrm{Z}=4.67, \mathrm{p}=0.008, \mathrm{k}=12$ \\
\hline & L $\quad$ Calcarine & $-20-688$ & $\mathrm{Z}=4.34, \mathrm{p}=0.029, \mathrm{k}=45$ \\
\hline & (occipital gyrus) & $-6-7210$ & $\mathrm{Z}=4.30, \mathrm{p}=0.034$ \\
\hline & L Lingual gyrus & $0-728$ & $\mathrm{Z}=4.21, \mathrm{p}=0.047$ \\
\hline & R Angular gyrus ${ }^{*}, \mathrm{~b}$ & $42-6638^{a}$ & $\mathrm{Z}=4.36, \mathrm{p}=0.027, \mathrm{k}=1$ \\
\hline & L Middle frontal gyrus & $-324820^{a}$ & $\mathrm{Z}=4.24, \mathrm{p}=0.043, \mathrm{k}=2$ \\
\hline $\begin{array}{l}(\mathrm{AA}+\mathrm{AG}> \\
\mathrm{GG}) \&(\mathrm{SCZ}> \\
\mathrm{CON})\end{array}$ & $\begin{array}{l}\mathrm{R} \text { Inferior frontal gyrus, } \\
\text { pars opercularis * }\end{array}$ & 601614 & $\mathrm{Z}=4.31, \mathrm{p}=0.032, \mathrm{k}=3$ \\
\hline $\begin{array}{l}\mathrm{AA}+\mathrm{AG}>\mathrm{GG} \\
\text { in PSYCH }\end{array}$ & R Precuneus ${ }^{*, b}$ & $14-5014^{a}$ & $\mathrm{Z}=4.24, \mathrm{p}=0.042, \mathrm{k}=1$ \\
\hline $\begin{array}{l}(\mathrm{AA}+\mathrm{AG}> \\
\mathrm{GG}) \&(\mathrm{PSYCH}\end{array}$ & $\begin{array}{l}\text { L Calcarine sulcus } \\
\text { (occipital gyrus) }\end{array}$ & $-20-6610$ & $\mathrm{Z}=4.69, \mathrm{p}=0.007, \mathrm{k}=53$ \\
\hline$>\mathrm{CON})$ & L Middle frontal gyrus & $-324818^{a}$ & $\mathrm{Z}=4.30, \mathrm{p}=0.033, \mathrm{k}=10$ \\
\hline 1.2. Effect o & $A C N A 1 C \times Z N F 804 A \mathrm{ge}$ & type inter & \\
\hline & L Precuneus $^{c}$ & $-2-5220$ & $\mathrm{Z}=5.05, \mathrm{p}=0.001, \mathrm{k}=223$ \\
\hline & R Precuneus $^{\mathrm{c}}$ & $2-5220$ & $\mathrm{Z}=4.73, \mathrm{p}=0.006$ \\
\hline & L Posterior cingulate gyrus $^{c}$ & $-2-5020$ & $Z=5.05, p=0.001$ \\
\hline$(\mathrm{AA}+\mathrm{AG}<$ & R Posterior cingulate gyrus $^{c}$ & $2-4416^{a}$ & $\mathrm{Z}=4.42, \mathrm{p}=0.021$ \\
\hline $\begin{array}{l}\mathrm{GG}) \&(\mathrm{AA}> \\
\mathrm{AC}+\mathrm{CC}) \text { in }\end{array}$ & $\begin{array}{l}\text { L Calcarine sulcus (occipital } \\
\text { gyrus) }\end{array}$ & $-2-5812$ & $\mathrm{Z}=4.42, \mathrm{p}=0.021$ \\
\hline $\mathrm{CON}$ & $\begin{array}{l}\mathrm{R} \text { Calcarine sulcus } \\
\text { (occipital gyrus) }^{\mathrm{c}}\end{array}$ & $2-5814$ & $\mathrm{Z}=4.31, \mathrm{p}=0.033$ \\
\hline & & $8-810$ & $\mathrm{Z}=4.75, \mathrm{p}=0.005, \mathrm{k}=237$ \\
\hline & & $2-202$ & $Z=4.64, p=0.009$ \\
\hline
\end{tabular}

This article is protected by copyright. All rights reserved. 


\begin{tabular}{|c|c|c|c|}
\hline & L Thalamus & $-2-204^{a}$ & $Z=4.40$ \\
\hline & L Lingual gyrus & $-8-362^{a}$ & $\mathrm{Z}=4.26, \mathrm{p}=0.040, \mathrm{k}=3$ \\
\hline & R Middle cingulate gyrus & $-2-2826^{a}$ & $\mathrm{Z}=4.24, \mathrm{p}=0.043, \mathrm{k}=2$ \\
\hline & R Superior temporal gyrus ${ }^{*, c}$ & $64-2216$ & $\mathrm{Z}=4.21, \mathrm{p}=0.048, \mathrm{k}=1$ \\
\hline \multirow{2}{*}{$\begin{array}{l}(\mathrm{AA}+\mathrm{AG}> \\
\mathrm{GG}) \&(\mathrm{AA}>\end{array}$} & 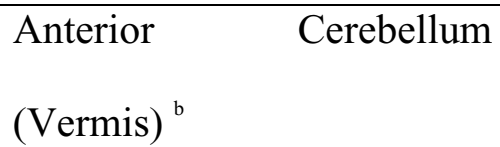 & $2-5010$ & $\mathrm{Z}=4.56, \mathrm{p}=0.012, \mathrm{k}=24$ \\
\hline & \multirow{2}{*}{ R Thalamus } & $8-414$ & $\mathrm{Z}=4.55, \mathrm{p}=0.013, \mathrm{k}=63$ \\
\hline $\mathrm{AC}+\mathrm{CC}) \&$ & & $4-1418^{\text {a,d }}$ & $\mathrm{Z}=4.37, \mathrm{p}=0.026$ \\
\hline \multirow[t]{2}{*}{$(\mathrm{BD}>\mathrm{CON})$} & L Caudate nucleus & $-14-416^{a}$ & $\mathrm{Z}=4.52, \mathrm{p}=0.015, \mathrm{k}=26$ \\
\hline & R Caudate nucleus & $12-214^{a}$ & $\mathrm{Z}=4.46, \mathrm{p}=0.018$ \\
\hline \multirow{2}{*}{$\begin{array}{l}(\mathrm{AA}+\mathrm{AG}> \\
\mathrm{GG}) \&(\mathrm{AA}> \\
\mathrm{AC}+\mathrm{CC}) \& \\
(\mathrm{SCZ}>\mathrm{CON})\end{array}$} & L Superior temporal gyrus & $-52-4412^{a}$ & $\mathrm{Z}=4.65, \mathrm{p}=0.008, \mathrm{k}=45$ \\
\hline & L Middle temporal gyrus & $-54-4410^{a}$ & $\mathrm{Z}=4.55, \mathrm{p}=0.012$ \\
\hline $\begin{array}{l}(\mathrm{AA}+\mathrm{AG}> \\
\mathrm{GG}) \&(\mathrm{AA}> \\
\mathrm{AC}+\mathrm{CC}) \& \\
(\mathrm{BD}>\mathrm{SCZ})\end{array}$ & R Caudate nucleus ${ }^{*}$ & $12-216^{\mathrm{e}}$ & $\mathrm{Z}=4.20, \mathrm{p}=0.049, \mathrm{k}=1$ \\
\hline $\begin{array}{l}\mathrm{AA}+\mathrm{AG}> \\
\mathrm{GG}) \&(\mathrm{AA}> \\
\mathrm{AC}+\mathrm{CC}) \& \\
(\mathrm{PSYCH}> \\
\mathrm{CON})\end{array}$ & $\mathrm{R}^{\text {Thalamus }}{ }^{*}$ & $6-1414^{\mathrm{a}, \mathrm{d}}$ & $\mathrm{Z}=4.20, \mathrm{p}=0.050, \mathrm{k}=1$ \\
\hline $\begin{array}{r}\text { 2. Psychophys } \\
\text { pars opercu }\end{array}$ & $\begin{array}{l}\text { ogical interaction with } \\
\text { ris (seed corresponding } t\end{array}$ & ecentral & $\begin{array}{l}\text { s/inferior frontal gy } \\
\text { ct of task) }\end{array}$ \\
\hline
\end{tabular}

This article is protected by copyright. All rights reserved. 


\begin{tabular}{|c|c|c|c|}
\hline \multicolumn{4}{|c|}{ 2.1. Effect of $C A C N A 1 C$ genotype } \\
\hline$(\mathrm{AA}+\mathrm{AG}>$ & L Superior temporal gyrus & $-52-4414^{a}$ & $\mathrm{Z}=5.07, \mathrm{p}=0.002, \mathrm{k}=60$ \\
\hline $\mathrm{GG}) \&(\mathrm{SCZ}<$ & L Middle temporal gyrus & $-52-4614^{a}$ & $\mathrm{Z}=4.80, \mathrm{p}=0.006$ \\
\hline $\mathrm{CON})$ & L Supramarginal gyrus & $46-4032^{a}$ & $\mathrm{Z}=4.29, \mathrm{p}=0.044, \mathrm{k}=2$ \\
\hline $\begin{array}{l}\mathrm{AA}+\mathrm{AG}< \\
\mathrm{GG} \text { in } \mathrm{SCZ}\end{array}$ & L Superior temporal gyrus ${ }^{*}$ & $-52-4414^{a}$ & $\mathrm{Z}=4.36, \mathrm{p}=0.034, \mathrm{k}=3$ \\
\hline $\begin{array}{l}\mathrm{AA}+\mathrm{AG}> \\
\mathrm{GG} \text { in } \mathrm{CON}^{\mathrm{f}}\end{array}$ & R Precuneus & $14-6234^{a}$ & $\mathrm{Z}=4.51, \mathrm{p}=0.018, \mathrm{k}=15$ \\
\hline
\end{tabular}

*Trend results: clusters with less than 5 clusters.

${ }^{\text {a }}$ Peak localized in the nearby white matter.

${ }^{\mathrm{b}}$ Region associated with decreased deactivation.

${ }^{c}$ Regions associated with increased deactivation.

${ }^{\mathrm{d}}$ Anterior part of the thalamus.

${ }^{\mathrm{e}}$ Medial part of the caudate nucleus.

${ }^{\mathrm{f}}$ Only present in the ANOVA comprising controls and patients experiencing psychosis. AA, adenine-adenine; AG, adenine-guanine, GG, guanine-guanine; BD, bipolar disorder; SCZ, schizophrenia; PSYCH, patients with a history of psychosis; R, right; L, left. 


\section{University Library}

\section{- M M N E R VA A gateway to Melbourne's research publications}

Minerva Access is the Institutional Repository of The University of Melbourne

\section{Author/s:}

Tecelão, D;Mendes, A;Martins, D;Fu, C;Chaddock, CA;Picchioni, MM;McDonald, C;Kalidindi, S;Murray, R;Prata, DP

Title:

The effect of psychosis associated CACNA1C, and its epistasis with ZNF804A, on brain function.

Date:

2019-04

Citation:

Tecelão, D., Mendes, A., Martins, D., Fu, C., Chaddock, C. A., Picchioni, M. M., McDonald, C., Kalidindi, S., Murray, R. \& Prata, D. P. (2019). The effect of psychosis associated CACNA1C, and its epistasis with ZNF804A, on brain function.. Genes Brain Behav, 18 (4), pp.e12510-. https://doi.org/10.1111/gbb.12510.

Persistent Link:

http://hdl.handle.net/11343/284823 